\title{
Escrita e poder: uma leitura do referencial curricular nacional para escolas indígenas
}

\author{
Jaçanã Ribeiro \\ Universidade Federal de Santa Catarina - UFSC
}

\begin{abstract}
RESUMO: O objetivo deste trabalho é problematizar, dialogar com um ponto crucial da proposta do Referencial Curricular Nacional para as Escolas Indígenas (RCNEI): discutir alguns aspectos das propostas de práticas de escrita e leitura sob o prisma da relação escrita-poder. Procuro partir do posicionamento de alguns autores dos estudos de letramento e estudos de gêneros e tipos de textos para, no plano dialógico da constituição do discurso, refletir sobre "pontos de fuga" da interpretação do documento que estão diretamente relacionados ao que se tem discutido como dicotomia evolução / aculturação do sujeito aluno índio. Proponho, assim, uma leitura que incide teoricamente não só sobre a proposta de práticas escritas para as escolas indígenas, mas que pretende dizer algo sobre o fracasso de nossa escola.
\end{abstract}

PALAVRAS-CHAVE: letramento indígena, escrita, poder.

ABSTRACT: The aim of this text is to argue about a crucial point of the proposal of the Referencial Curricular Nacional para as Escolas Indígenas (RCNEI): we should reflect on certain aspects of the practices of writing and reading under the perspective of the relation between literacy-power. Based on authors of the literacy studies and genre and text types, my aim is to investigate, on the dialogic plan of constitution of discourse, interpretations on the document regarding what is so called the dichotomy evolution / acculturation of the indian student. Thus I propose an interpretation that is relevant not only to the literacy practices of the "indian school", but also to explain part of the failure of our schools.

KEY-WORDS: indian literacy, writing, power.

\section{Introdução}

No quadro da política de inclusão do sujeito índio na sociedade brasileira, está reservado pela Constituição seu direito à educação fundamental e média em sua própria língua materna. Sabemos que tal conquista não é movida apenas por vontades solícitas de políticos e servidores bem-intencionados, bem como pesquisadores tais como 
antropólogos, pedagogos etc., mas nasce no centro de um movimento de luta e organização indígena constante para garantir tal direito. Tanto é assim que cada vez mais se procura aprimorar a educação dita bilíngüe e diferenciada direcionada a esses sujeitos, hoje já bem diferente daquela ministrada pelos missionários religiosos que pretendiam sub-repticiamente catequizar os índios através da alfabetização, para leitura e tradução da Bỉblia. ${ }^{1}$ É nesse sentido que, em 1998, uma equipe coordenada por membros do Comitê de Educação Indígena elaborou o documento chamado de Referencial Curricular Nacional para as Escolas Indígenas (RCNEI), ${ }^{2}$ que vem ampliar e esmiuçar os princípios traçados no documento "Diretrizes para a Política Nacional de Educação Escolar Indígena" de 1993, fazendo conjunto com os Parâmetros Curriculares Nacionais. O objetivo do documento, como consta no seu texto, é "promover uma educação intercultural e bilíngüe, assegurando a interação e parceria na oferta de subsídios e orientações para a elaboração de programas de educação escolar que melhor atendam aos anseios e interesses das comunidades indígenas". Tem como interlocutores privilegiados, nesse sentido, profissionais que têm por responsabilidade a implementação e regularização de programas educativos nas comunidades indígenas, bem como serve de documento formador de professores indígenas.

No entanto, apesar da legitimidade da interpretação desses sujeitos, suas proposições devem servir de ponto de partida para discussões e não devem ser tomadas como fórmulas a serem aplicadas direta e independentemente da realidade da comunidade escolar. Ora, essa é uma observação importante que consta no próprio RCNEI, que reconhece que a realidade das populações indígenas é marcadamente plural e diversificada, seja pela realidade plurilingüística existente (são aproximadamente 180 línguas indígenas no país), seja pela variedade sociolingüística (monolinguismo, diglossia, ausência de variedade padrão formal), ou mesmo pela variedade étnica das tribos (questão de extrema relevância, haja vista o primado da inclusão de conhecimentos étnicos ao currículo escolar). Assim sendo, buscou-se um consenso mínimo na elaboração desse documento, que é textualmente

\footnotetext{
${ }^{1}$ Como no caso bastante comentado do Summer Institute of Linguistics, SIL, responsável por grande parte do material didático do ensino bilíngüe "missionário" no Brasil.

${ }^{2}$ Faremos referência ao documento ao longo do trabalho utilizando essa sigla e (MEC, 1998).
} 
apresentado como sujeito a diferentes leituras e interpretações como subsídio a novas políticas pedagógicas e curriculares.

O objetivo deste trabalho é problematizar, dialogar com um ponto crucial da proposta do RCNEI: discutir alguns aspectos das interpretações relativas à relação escrita-poder a partir de alguns elementos teóricos, sobretudo com base nos estudos de letramento. Assim sendo, não tomamos o sentido da proposta como fechado em si mesmo, como os próprios autores advertem a não proceder. Procuramos antes refletir sobre a proposta em sua constituição dialógica, não no intento de dizer de outro modo o que já nela está dito, mas arriscando dizer o que se pode produzir nas bordas de sua constituição, tentando descrever o sentido como os contornos de uma ilha em relação ao oceano, segundo a metáfora bakhtiniana - um acontecimento que se caracteriza pela apreensão do sentido, pelo outro, em um movimento histórico.

Antes de apontar para uma questão mais pontual, trazemos à tona a questão abrangente em nível teórico e extremamente complexa - e que por isso merece sempre retorno - da caracterização do produto da constituição dialógica que Bakhtin também interpretou como evolução: "a apreensão da orientação que é conferida à palavra por um contexto e uma situação precisos, uma orientação no sentido da evolução e não do imobilismo" (BAKHTIN, 1997, p. 94).

Assim, discutiremos aqui alguns "pontos de fuga" da interpretação do documento que estão diretamente relacionados à dicotomia evolução / aculturação do sujeito aluno índio: questão fundamental no quadro da reflexão sobre a formação do professor indígena. Atentaremos, assim, para a constituição dialógica do texto do RCNEI, sobretudo para o que cremos ser um dos pontos nodais da questão: o letramento indígena. Mais precisamente, procuramos partir do posicionamento de alguns autores dos estudos de letramento e alfabetização (GEE, 2005; KLEIMAN, 1989, 1995; TFOUNI, 1995) e estudos de gêneros e tipos de textos (BRONCKART, 1997; ROJO, 2005).

$\mathrm{Na}$ primeira parte deste texto, a partir de alguns recortes do texto do RCNEI, especialmente da parte intitulada "Línguas", em que se explicita a proposta curricular bilíngüe, procuramos evidenciar a mediação da escrita na relação sujeito-poder, tomando como exemplos depoimentos de professores indígenas impressos nas margens das páginas do texto oficial. Na segunda parte, aprofundando a questão através de uma aproximação com os estudos de gênero, analisamos brevemente as propostas de práticas de escrita sugeridas pelo RCNEI. 


\section{Letramento, escritismo e poder}

Os chamados estudos do letramento colocam em questão uma concepção muito mecânica da alfabetização como apreensão de um código, a partir da problematização da dimensão sócio-cultural da língua escrita e de seu aprendizado. A concepção de letramento, tal como apresentada por pesquisadores como Kleiman (1995) e Tfouni (1995), contribuiu para redimensionar a compreensão de numerosas questões relativas às dimensões do aprender a ler e a escrever, tanto do lado do aluno quanto do professor, entendidos não como pólos de uma dicotomia, mas como agentes em interação. Além disso, as pesquisas têm por objeto questões que tratam dos significados do aprender a ler e a escrever, da caracterização de uma sociedade letrada brasileira, dos motivos pelos quais tantos deixam de aprender a ler e a escrever, entre outras questões (KLEIMAN, 1995).

A grande contribuição desses estudos é o fato de que consideram a escrita não só como código formal, mas antes partem de um ponto de vista cultural e social da escrita em sua dimensão prática. A pesquisa sobre alfabetização, nessa perspectiva, procura dar conta do processo de inserção do sujeito numa cultura letrada, tendo como objeto de reflexão o uso social da leitura e da escrita. "Assim, [e]nquanto a alfabetização se ocupa da aquisição da escrita por um indivíduo, ou grupo de indivíduos, o letramento focaliza os aspectos sócio-históricos da aquisição de uma sociedade" (TFOUNI, 1995, p. 20).

Os estudos de letramento, ao tratarem da prática da escrita e da leitura no âmbito social, são sensíveis também ao âmbito político e à questão do poder intimamente envolvida nessas práticas. Na aproximação possível com a Análise Crítica do Discurso de Fairclough (1992/2001), o letramento está intrinsecamente relacionado a uma prática de empowerment (empoderamento), que capacita o sujeito a interagir politicamente na mudança social, o que implica que letrar é mais do que alfabetizar (ensinar um código). Assim, sob a ótica de um grupo social de tradição escrita, não restaria dúvidas quanto ao valor político desse empoderamento do letramento - afinal, para exercer um mínimo de cidadania é necessário conhecer as leis, que sempre estão escritas em uma variedade de prestígio, em um registro formal. Entretanto, a questão se complica consideravelmente se tomamos a situação de letramento do sujeito índio, cujo grupo social não tem uma tradição escrita como a ocidental, e para quem as funções sociais da escrita só não são opacas quando se coloca na perspectiva do 
dominador: como é um cidadão brasileiro, tem o direito (dever) de conhecer (ler) as leis de seu país - perspectiva jurídica. De todo modo, porém, essa escrita, cuja prática se impõe, é a escrita do português, a escrita do outro; ponto complexo na política pedagógica indígena: o sujeito índio não pratica espontaneamente a escrita de sua língua materna, pois esta é de tradição ágrafa. Dentre outros pontos que discutiremos, está a correlação irredutível entre a existência da prática da escrita no âmbito social e seu aprendizado na escola, o que, no caso do letramento em língua indígena, pode significar uma inversão da relação tal como ela se estabelece em nossa sociedade, descrita da seguinte maneira por Ferreiro (2001): "[a] escrita (nas sociedades de tradição escrita) é importante na escola, porque é importante fora dela e não o contrário".

Nesse sentido, é claro que a prática do letramento escolar pressupõe a associação, não só para a língua portuguesa mas também para a língua indígena, entre uma determinada variedade lingüística e a escrita dessa variedade, tomada como forma da variedade padrão legitimada. ${ }^{3} \mathrm{Tal}$ associação, como lembra Gnerre (2003), implica um processo de "elaboração" dessa variedade que nasce no seio de conflitos entre grupos sociais que são usuários de diferentes variedades, o que acarreta uma estandardização que tem como contrapartida a discriminação e dominação de todas variedades que não a tomada como padrão. Esse aspecto do ensino da escrita fica bastante explícito se consideramos as culturas sem tradição escrita e a introdução, através de políticas públicas, da prática de letramento escolar, tal como escreve Lévi-Strauss sobre sua experiência específica entre os Nhambikuara do Brasil, uma sociedade de tradição oral:

\begin{abstract}
Ainda que a escrita não tenha sido suficiente para consolidar o conhecimento, ela foi talvez indispensável para fortalecer a dominação... A luta contra o analfabetismo está em relação com um crescimento da autoridade dos governos sobre os cidadãos. Todos têm que ser capazes de ler, de forma que o governo possa dizer: a ignorância da lei não é desculpa (LÉVISTRAUSS, 1974, p. 336-338).
\end{abstract}

Esse é um dos aspectos que não estão explícitos no RCNEI e que deve ser discutido entre os agentes da prática pedagógica, tomando como ponto de partida uma concepção da escrita enquanto prática social mediada

\footnotetext{
${ }^{3}$ No caso da Língua Kaingáng, para citar um exemplo, quem a estudou e sugeriu a ortografia oficial foi a lingüista americana Ursula Wiesemann, trabalhando para o Summer Institute of Linguistics.
} 
pela intervenção do Estado. Obviamente a questão do poder não é deixada de lado pelos estudos do letramento, como veremos adiante.

É interessante observar, nesse sentido, que, mesmo que essa relação não seja problematizada no texto do RCNEI - não existe discussão clara sobre a natureza dominadora da política governamental, pois a proposta se apresenta como uma reivindicação do cidadão índio -, ela aparece, no entanto, nos depoimentos dos professores indígenas que acompanham o desenvolvimento do texto, nas margens das páginas. Esses depoimentos, se lidos na perspectiva do RCNEI, servem para sustentar sua posição e trazem legitimidade da parte das comunidades escolares indígenas. No entanto, podemos lê-los como sendo testemunhos de uma subjetivação ao poder, principalmente quando reproduzem posicionamentos típicos da cultura dominante:

A Língua hoje para mim é um documento. Eu não falava. Tinha vergonha. Meu velho pai falava. Hoje eu já falo. Sei muitas coisas e sei ensinar para quem quiser dessas meninadas. E já temos até essa língua escrita no papel, mesmo que ainda tenha alguns erros para consertar. Hoje o vereador e o prefeito ficam admirados com a Língua. Com essa escrita. Acho que ficam pensando: "esses caboclos têm uma língua mesmo..." Antes ela não aparecia (Mário Cordeiro, professor Poyanawa, AC, MEC, 1998, grifos nossos)

Salta aos olhos a associação entre prestígio reconhecido pelo poder e existência de variedade escrita da língua indígena. Oliveira (1997), em texto que problematiza a "delicada questão da assessoria lingüística ao movimento indígena", chama a atenção para o "preconceito lingüísticopolítico" que se tem chamado de "escritismo" no ensino bilíngüe indígena. Ao mesmo tempo em que se defende um ensino diferente e específico para os povos indígenas, dá-se mais valor às formas de conhecimento escritas em detrimento da oralidade. No depoimento, além de falar do vereador e do prefeito, o professor valoriza ainda o processo de definição da variedade escrita, processo de "redução" das formas orais da língua para os moldes

\footnotetext{
4 "Escritismo", na definição de Harris (1980 apud OLIVEIRA, 1997), é a "tradição que define a escrita como uma forma superior de expressão do conhecimento por ter eliminado as barreiras do tempo e da memória. Os sistemas de conhecimento baseados na escrita são tidos como superiores às formas de conhecimento orais. Outra característica dessa tradição é considerar a possibilidade de transpor com fidelidade os sistemas de conhecimento oral para a escrita".
} 
da racionalidade escrita, pela possibilidade de acertar os erros que ainda existem... ${ }^{5}$

Os estudos de letramento, em contrapartida, têm mostrado que não é possível falar em valor da escrita em si, sempre situando tanto seu ensino como sua produção em uma prática social definida. Um dos perigos que uma abordagem abrangente como a do RCNEI pode provocar é o do apagamento da especificidade da relação do índio com a escrita, o que não esconde a dominação pela imposição de uma prática externa que não é a sua. A prática da escrita da língua indígena nasce, assim, do letramento que possibilita a inclusão do cidadão brasileiro índio, mas lhe expõe o exterior da escrita no qual se identifica como sujeito falante de uma língua ágrafa.

O depoimento do professor índio vai bem ao encontro do texto que o introduz e que reduplica a divisão preconceituosa entre línguas de prestígio / línguas sem prestígio, além de associar o prestígio à existência de formas narrativas/textuais (das quais falaremos adiante) próprias de nossa sociedade de tradição escrita. Diz o texto do RCNEI:

Quando a língua indígena for escrita, ela aparecerá em cartilhas, gramáticas, dicionários, antologias de textos etc. O fato de terem suas línguas tradicionais publicadas, descritas e documentadas - assim como acontece com as línguas de prestígio no mundo inteiro - tem sido motivo de orgulho e satisfação para muitos povos indígenas (MEC, 1998, p 120).

A escrita, para o "escritismo", é um bem em si mesmo, um bem universal, fruto da evolução humana, e a capacidade de ler e de escrever é defendida como intrinsecamente boa, apresentando vantagens necessárias sobre a pobreza da oralidade. ${ }^{6}$

\footnotetext{
${ }^{5}$ Sem dúvida, ainda que percebam a ocorrência de equívocos na linguagem oral, a noção de erro de escrita aparece como uma exportação para a cultura indígena. Uma pergunta assim se impõe: o aluno indígena que não souber escrever em sua língua será reprovado na escola?

${ }^{6}$ Sobre essa visão limitada do letramento, ver Graff (1979; 1994). Esse autor denuncia o que chama de "mito do letramento", que, com base em correlações simplistas entre o letramento e formas superiores de pensamento, condena uma interpretação dominante e hegemônica de um impacto significativo, independente e absolutamente positivo do letramento. Graff, a partir de uma visão histórica, busca desmistificar as "bases morais" do letramento e abalar a crença na linearidade e infalibidade da ligação progresso-letramento.
} 
Diante desse quadro, para os pesquisadores envolvidos que são sensíveis a esse problema, o que se propõe como solução é a tentativa de abordar a prática do letramento escolar como uma interpretação recíproca, dialógica, o máximo possível. Diferentemente do que ocorre, em grande medida, no letramento de alunos ocidentais, que estão em contato diário com o mundo simbólico da escrita, desde que nascem, os alunos indígenas não têm esse contato, ou o tem muito pouco, e se o têm é com a escrita do português. Antes, contadores de histórias memorizadas e dificilmente exatamente repetidas; hoje, o professor indígena se vangloria de produzir suas narrativas como nós:

Uma das línguas que mais atuam aqui no Brasil é a língua portuguesa, mas a gente sabe que a nossa língua também é de grande importância. E a gente perdeu muitas histórias, muitos casos passados que a gente agora podia ter e contar para os nossos filhos. Vamos supor, você sabe de uma história que é Yawaxikunawa. Antes de você morrer, se você não contar para o seu filho, o seu filho não vai saber nada dessa história. Então a gente quer registrar um pouquinho dos mitos. E a escrita da língua vai ser muito importante para nós porque, no momento em que você quiser fugir de algum branco, dizer para ele escondido, você vai fazer uma escrita dizendo "olha, eu estou passando por uma coisa assim, assim..." e só você que vai saber ler, o branco não vai saber (Joaquim Maná, professor Kaxinawa, AC, MEC, 1998).

No entanto, inversão da "aprendizagem" em "apreensão", "invenção", o professor sabe bem que tem em suas mãos uma arma - contra aquele que o ensinou a "codificar". Sabe que ela tem o poder da diferença (não compreensão) na semelhança do poder (simbólico). Esse tipo de consideração, esse detalhe, não chega a ser objeto de tema no RCNEI.

Podemos tomar agora dois trechos do texto do RCNEI para exemplificar, de um lado, como o poder se manifesta na tentativa de inclusão do saber do outro, no modo como procura subsidiar a prática dialógica, e, de outro, a impossibilidade de não apresentar suas formas de conhecimento como parâmetros a serem cobrados pela escola. O caráter fortemente dialógico da constituição do RCNEI fica claro nas duas passagens seguintes:

O documento (RCNI) divide-se em duas partes. Na primeira, "Para começo de conversa", estão reunidos os fundamentos históricos, políticos, legais, antropológicos e pedagógicos que balizam a proposta de uma escola indígena intercultural, bilíngüe e diferenciada (MEC, 1998, p. 9).

Não é necessário acrescentar, obviamente, que os fundamentos propriamente indígenas que balizariam qualquer proposta de escola 
indígena estão aqui representados, escritos, na voz de seus intérpretes mais acurados, os antropólogos. Além disso, há os fundamentos "históricos", num certo modo de ver a história, os "legais", sob a ótica de uma jurisprudência universal, e os "pedagógicos", que incluem uma certa escrita como bem da humanidade. Em suma, para reconhecer o outro, é necessário identificá-lo sob a sua própria lente. É o que se vê mais pontualmente na seguinte passagem:

Na segunda parte, "Ajudando a construir o currículo nas escolas indígenas", apresenta-se, a partir das áreas de conhecimento, sugestões de trabalho para a construção dos currículos escolares indígenas específicos a cada realidade. Isso é concretizado a partir de indicações de seis temas transversais (auto-sustentação; ética indígena; pluralidade cultural; direitos, lutas e movimentos; terra e preservação da bio-diversidade; e educação preventiva para a saúde) e do trabalho com seis áreas de estudos (línguas, matemática, geografia, história, ciências, arte e educação física). A proposta desta parte do documento é uma integração entre conhecimentos universais selecionados e os etno-conhecimentos de cada povo indígena (Ibidem).

Sobre essa passagem, os estudos do letramento e as teorias de gêneros textuais podem nos esclarecer sobre um ponto importante relativo à possibilidade de interpretação recíproca, dialógica, no letramento indígena. Há, no texto, uma divisão clara entre o que poderíamos chamar de dois campos de discurso: uma dicotomia divide a proposta curricular entre "conhecimentos universais", representados pelas disciplinas que conhecemos bem, e "etnoconhecimentos" de cada povo, enquadrando esses "etno-conhecimentos" dentro das categorias acima enumeradas: auto-sustentação; ética indígena; pluralidade cultural; direitos, lutas e movimentos; terra e preservação da biodiversidade; e educação preventiva para a saúde. Todas essas categorias podem ser tomadas como práticas de discurso, em que há uso social, seja da escrita seja da leitura e de sua relação com o mundo. Entre essas categorias, sabemos que não há limites precisos, o que não está assumido obviamente pelo RCNEI, mas relações de constituição recíproca enquanto práticas heterogêneas de discurso. Assim, a dicotomia parece bastante opaca sob uma ótica de letramento enquanto prática, afirmando a separação equívoca entre universal e étnico. Além disso, poderíamos ir até mais longe e perguntar sobre a relação que existe entre essas práticas de escrita - formas de hierarquizar e dividir o conhecimento - e o caráter fragmentário, compartimentado e descontextualizado do saber escolar ocidental. Gnerre (2003), num exercício de interpretação recíproca, que é na verdade a tentativa de interpretar (antecipar) a interpretação do outro, chega a imaginar que 
os absurdos dessa instrução escolar, para alguém que participe de formas discursivas próprias de sociedades de tradição oral, sejam ainda mais imediatos e reconhecidos. O autor lembra a história da reinvindicação do líder dos índios de Télan-Chismute, do Equador Central, ao padre responsável pela escola indígena: "que não ensinem besteiras, padrecito, porque montanha da África, Kilimanjaro, é mesmo uma besteira, padrecito" (ORTIZ CRESPO, 1983 apud GNERRE, 2003, p. 102).

Nesse sentido, a tentativa louvável e consciente de inserir os conhecimentos étnicos ao currículo não pode ser realizada de outro modoe essa é a evidência da dimensão do poder na formulação desse documento - senão apresentando-os a partir de nossa grade codificadora, de nosso arquivo, ${ }^{7}$ no sentido de Foucault (2004).

Tendo analisado algumas passagens relativas à dimensão do poder na formulação da proposta do Estado, reafirmo que essa análise tem como objetivo uma interpretação crítica do RCNEI, com base nos estudos de letramento e da Análise Crítica do Discurso. Também é claro que não pretendo, e me faltariam certamente possibilidades e espaço, apresentar uma solução para os impasses da constituição dialógica do texto; assim, limito-me a apontar pontos de partida para suscitar o aprofundamento da questão; não fechar o texto, mas abri-lo à problematização.

\section{Letramento, discurso e gêneros textuais}

No texto "La ideología en los Discursos", o educador e lingüista James Paul Gee (2005) apresenta uma divisão interessante entre discursos primários e discursos secundários. Segundo esse autor, os discursos primários são aqueles que configuram nossa primeira identidade social, espécie de base de idéias iniciais e indiscutidas sobre quem somos e de quem é como nós, nossos valores quando estamos "em público". Já os discursos secundários estão ligados à nossa participação social, nossos atos públicos nos grupos e instituições, por exemplo, igrejas, escolas, trabalho.

A distinção, como afirma Gee, não é carente de problemas, mas tem a vantagem de apresentar, quando se pergunta sobre o acesso das pessoas

\footnotetext{
${ }^{7}$ Assim se coloca mais uma questão crucial da proposta: o "arquivo" indígena até então se constitui numa relação estritamente oral. O que implica para o modo próprio que cada cultura tem de organizar suas formas de saber a introdução da escrita?
} 
a esses dois tipos de discurso, uma diferença entre aquisição e aprendizagem, uma divisão que se apresenta como um contínuo, e não é de modo algum estanque.

Aqui, a diferença é importante pelo fato de a aquisição ser um processo primário que se dá, por regra geral, de forma subconsciente, mediante o contato com modelos, tentativa e erro, em ambientes naturais, significativos e funcionais. Por outro lado, a aprendizagem pressupõe o contato com os discursos numa perspectiva de objetivação consciente de regras, passível de ensino, produzindo uma reflexão que decompõe o objeto em suas partes; em suma, pressupõe um metaconhecimento.

Ao aproximar o tema da alfabetização com o dos discursos e, mais especificamente, com as duas classes de discurso apresentadas anteriormente, Gee considera que a alfabetização deve ser sempre concebida como um processo de aquisição (e não aprendizagem) de um discurso secundário: "Creo que cualquier definición socialmente útil de alfabetización debe formularse em términos de estas ideas de los Discursos primários y secundários. Por tanto, defino la alfabetización como el domínio de um Discurso secundário" (GEE, 2005, p. 156).

A alfabetização, portanto, é produto da aquisição e não da aprendizagem, requer contato com os modelos em ambientes naturais, significativos e funcionais, não sendo provável, como o autor enfatiza, que o ensino tenha muito êxito nesse caso, podendo inclusive ser um obstáculo. Desnecessário dizer que essas considerações podem nos ajudar a compreender não somente a situação do letramento indígena mas também o próprio iletrismo na sociedade brasileira.

Nessa perspectiva, estamos distantes da concepção de escrita como um bem em si. Antes, para que haja letramento, é necessário que exista a prática social da escrita: "Si carecemos de acesso a la prática social, no nos introducimos en el discurso, no lo tenemos" (Ibidem, p. 154).

Entretanto, não devemos entender por isso que a aquisição seja autosuficiente para o que o autor chama de alfabetização libertadora. ${ }^{8}$ A alfabetização libertadora, de posicionamento crítico, consciente da relação entre o acontecimento e o modelo, pressupõe a aprendizagem, um metaconhecimento do discurso. O fato para o qual chamamos a atenção

${ }^{8}$ A fonte primária dessa concepção de ensino, como sabemos, é a proposta de Paulo Freire. 
aqui é a alternativa que resta, a partir dessa perspectiva, para a proposta curricular do RCNEI: inventar uma prática social de escrita - fora da escola - para as comunidades indígenas.

Essa invenção implica uma série de identificações e des-identificações no plano do discurso que são referentes àquilo que faz com que um sujeito seja sujeito de uma prática, ou seja, as regras do jogo de uma prática simbólica, as quais não caem do céu e são socialmente constituídas na história, diferentemente em cada cultura. Para escrever, seja em português, seja em língua indígena, o aluno é, sempre e ao mesmo tempo, sujeito de e sujeito à aculturação que sustenta a instituição escolar, o que o compromete a aceitar ou não as regras desse discurso secundário que mantém relações diversas com os discursos primários (formas discursivas da oralidade) aos quais tem acesso. Tal aspecto das práticas de letramento escolar evidencia sua constituição num embate de forças sociais:

Há uma dimensão de poder envolvida no processo de aculturação efetivado na escola: aprender - ou não - a ler e escrever não equivale a aprender uma técnica ou um conjunto de conhecimentos. O que está envolvido para o aluno adulto é a aceitação ou o desafio e a rejeição dos pressupostos, concepções e práticas de um grupo dominante - a saber, as práticas de letramento desses grupos entre as quais se incluem a leitura e a produção de textos em diversas instituições, bem como as formas legitimadas de se falar desses textos -, e o conseqüente abandono (e rejeição) das práticas culturais primárias de seu grupo subalterno que, até esse momento, eram as que the permitiam compreender o mundo. (KLEIMAN, 1995, p. 271).

Cremos que, no momento de subsidiar as propostas pedagógicas dos professores indígenas, o texto do RCNEI apresenta alguns desses "pressupostos, concepções e práticas" de grupo dominante. Tomamos dois pontos, apenas com o intuito de, mais uma vez, a partir da análise da constituição dialógica desse texto, expor o olhar leitor do professor em formação a diferentes leituras do RCNEI. Primeiramente, discutiremos brevemente o que chamamos de forma leitor e forma escritor. Depois, passaremos para uma associação entre as práticas de letramento e os gêneros textuais propostos no material de referência. Duas faces, como se vê, da prática da escrita: seu sujeito e seu texto. 


\section{As formas escritor e leitor}

O texto do RCNEI, na seção chamada "O desenvolvimento da linguagem escrita", o subtítulo "Tornando-se bons leitores e escritores" pretende, a partir da premissa inicial de que "a escrita é uma atividade que exige muito mais reflexão e elaboração do que a oralidade" (MEC, 1998, p. 138), caracterizar uma forma boa de escritor e outra, de leitor. Embora dito em outras palavras e talvez não tão diferentemente, o texto dos PCNs de Língua Portuguesa também traz a especificação de uma forma leitor e escritor, tal como diz Rojo (2005):

A visão de leitor/produtor de textos presente nos PCNs é a de um usuário eficaz e competente da linguagem escrita, imerso em práticas sociais e em atividades de linguagem letradas, que, em diferentes situações comunicativas, utiliza-se dos gêneros do discurso para construir ou reconstruir os sentidos de textos que lê ou produz (ROJO, 2005, p 35).

No RCNEI, um "bom escritor" é definido como aquele que sabe empregar a linguagem adequada com relação ao grau de formalidade da situação; é também aquele que sabe escolher os melhores argumentos e que elabora esquemas, rascunhos e versões iniciais antes de dar por prontos seus textos. Já o "bom leitor", caracteriza-se inicialmente pela capacidade de escolba entre os textos disponíveis ao seu acesso, depois pela capacidade de ler de forma não-linear, de ter uma "liberdade enorme" com relação aos textos; finalmente:

Também é característica do leitor fluente a sua capacidade de ler silenciosamente, sem necessidade de mexer os lábios. O bom leitor não precisa "ler" letra por letra, sílaba por sílaba. Essa capacidade permite também uma boa leitura em voz alta, quando este tipo de leitura é necessário (MEC, 1998, p. 139).

Com respeito a essa caracterização, este é realmente um ponto de maior complexidade para o letramento indígena. Com base no trecho de Rojo, as palavras "imerso em práticas sociais e em atividades de linguagem letradas" significam algo; ou seja, assim como autores como Chartier (1999), dos estudos históricos e culturais, e Kleiman, dos estudos do letramento, nos lembram, a definição de uma norma de leitura ou escrita, por exemplo, a leitura silenciosa e conduzida pelos olhos, são construções discursivas situadas na história, mais exatamente imposições tardias que definem o critério de 'iletrismo' a partir da relação com uma exterioridade. Com base nisso, acreditamos que seja necessário se perguntar se o sujeito escritor ou 
leitor indígena deve seguir essas características citadas acima para ser aprovado na escola. De qualquer modo, se no seio de uma mesma sociedade (força da categorização) há sutilezas inesperadas da relação do sujeito com o letramento, o que impede que isso ocorra numa outra sociedade, e de forma totalmente diferente? É interessante dizer que, a esse respeito, para os estudos da história da leitura, podemos falar de no mínimo três categorias de leitor na história. O leitor contemplativo dos séculos XVII e XVIII; o leitor movente das metrópoles aceleradas, lendo muitos textos diversificados em diferentes lugares; e o leitor imersivo, aquele que, ao surfar, mergulha no mar dos hipertextos e hipermídias da web. A conclusão desses estudos é que não existe o livro e, sim, um determinado livro, que se apresenta a um leitor determinado e não ao leitor, dadas as condições individualizantes desse processo que envolvem desde a visão de mundo, o conhecimento prévio, até os limites sintáticos e semânticos impostos ao autor, no momento da criação, e ao leitor, na recepção (MANGUEL, 1997). Assim, deixando de lado, por um momento, a nossa não-linearidade atestada na produção de versões consecutivas de um mesmo texto - em contraposição ao perfil do bom escritor e à nossa "capacidade de escolha" sob o jugo do desconhecimento forçado (CHARTIER, 1999) - em contraposição ao bom leitor, devemos imaginar um sujeito-aluno índio, escrevendo várias vezes um texto profissional (como um artigo de revista ou científico) em língua indígena ou indeciso frente à pletora de textos escritos na sua língua.

\section{Gêneros textuais e tradução cultural}

Trazemos as considerações dos gêneros textuais apresentados no Referencial porque acreditamos que eles estão intimamente ligados à caracterização do bom leitor e escritor. No RCNEI, ainda na seção sobre como se tornar um bom leitor/escritor, há a apresentação de possibilidades de práticas para a sala de aula, pois "a escrita pode ser utilizada para a produção de diferentes tipos ou modalidades de texto" (MEC, 1998, p. 140). Conforme o RCNEI, embora haja uma maior variedade de textos em português, os alunos devem entrar em contato com a maior diversidade de texto possível, em ambas as línguas.

De acordo com os estudos de gênero textual/discursivo, tais tipos ou modalidades não são formas nem moldes a que se devem obedecer. São, antes, o resultado de uma discursividade que se produz historicamente e cujo sujeito está inserido em uma formação social definida (BRONCKART, 
1997). São, portanto, o objeto de estudo de um vasto campo de pesquisa em que se incluem os chamados estudos dos gêneros textuais ou dos gêneros discursivos, que se enquadram, no Brasil, nas pesquisas do campo da Lingüística Aplicada. Como apresenta Rojo (2005), há muita divergência em suas metodologias, havendo abordagens analíticas que priorizam situações de enunciação em seus aspectos sócio-históricos, outras que analisam a estrutura ou forma composicional dos gêneros e mesmo aquelas que se detêm mais especificamente na materialidade lingüística da situação de enunciação, nas "marcas lingüísticas". No entanto, todas as vias metodológicas mantêm um diálogo com a obra bakhtiniana: todas sustentam uma interdependência entre o domínio da ação social propriamente dita e o domínio das produções de linguagem - relação que não é mecânica e que está na dependência de um domínio histórico.

Em função de seus objetivos, interesses e contextos específicos, as formações sociais elaboram diferentes espécies ou 'famílias' de textos que apresentam características suficientemente estáveis para que as qualifiquemos como 'gêneros'. Esses gêneros estão disponíveis no interdiscurso como modelos indexados pelos contemporâneos e as gerações posteriores (BRONCKART, 1997 apud ROJO, 2005, p. 191).

Está dito, assim, que as práticas de escrita e leitura não são independentes de uma prática social definida. Queremos argumentar, aqui, que o modo de apresentação dos tipos de texto do RCNEI é outro momento em que, por falta de tipos de texto indígenas a sugerir, não é explicitada a relação entre as propostas sugeridas e os modos de viver, típicos da nossa sociedade; antes são mostrados como modos de desenvolver capacidades cognitivas, o que produz a neutralização das nossas concepções e pressupostos dominantes. ${ }^{9}$ Trarei apenas um exemplo:

\footnotetext{
${ }^{9}$ Um dos "tipos textuais", notadamente o primeiro listado no RCNEI, é "contos, crônicas, histórias, relatos". Aqui aparece um ponto de contato em comum que poderia favorecer o desenvolvimento da escrita - e, de fato, é o tipo de texto que mais se produz (na escola) - através da produção da narrativa diferente. Como vimos em um dos depoimentos, é fazendo uso desse gênero que os índios se orgulham de escrever, registrar suas narrativas míticas e de relatos de histórias dos antigos. Comentário do RCNEI: "é nesse tipo de textos, se escritos em português, que freqüentemente aparecem expressões típicas de discursos orais indígenas ("sim, eu vou contar", "no tempo de antigamente", "os mais velhos contam").
} 
- Receitas, Bulas, Rótulos, Manuais de Instrução, Regulamentos e Listas

Esse tipo de texto, como os outros, é apresentado como tendo por função principal listar instruções a serem seguidas numa certa ordem. Ainda que haja a menção textual de que culturas diferentes têm critérios diferentes de ordenação de listas, a sugestão para a prática não contempla (afinal, qual seria o exemplo) listagens praticadas mesmo oralmente pelos índios, mas incentiva a ler listas de palavras em dicionários, listas de povos e das línguas indígenas existentes no país, listas de horários de saídas de ônibus, de marcas e preços de motores, e podem elaborar listas de plantas medicinais, de árvores nativas, de animais, de artesanato (MEC, 1998, p. 142). Tal sugestão tem, em seu bojo, a afirmação das características do tratado científico-expositivo, que preza pela sinteticidade, a clareza e a ordem, possivelmente o tipo de produção escrita que mais se distancia de qualquer gênero de produção oral. Na página 142 do RCNEI, extraído do Livro de Receitas Xacriabá, MG, é apresentado o seguinte texto ilustrativo:

\section{Raspa de juá-de-boi}

Serve para curar diarréia

\section{Modo de preparo}

- Primeiro raspe a entrecasca do juá, coloque dentro de uma vasilha e misture um pouco de água.

- Depois pegue um pedacinho de pau e vá mexendo até ficar bem agitado.

- Aí então tire aquela espuma que vai ficar por cima da vasilha e pode tomar aquela água que fica por baixo.

\section{Modo de usar}

- Tome um copo de hora em hora.

O exemplo acima, escrito por um sujeito-autor índio, pode servir bem de exemplo daquilo que Gnerre (2003) chama de "armadilha teórica" da alfabetização indígena, segundo a qual não é possível identificar nenhuma experiência de fixação da escrita de uma língua de tradição oral que não acabe por "traduzir" conteúdos referenciais expressos em línguas de culturas escritas. Nesse processo, há uma transferência de macromodalidades discursivas de uma variedade de língua escrita, tidas como mais fiéis e exatas para codificar o mundo, para o funcionamento discursivo de uma língua de tradição oral. "É importante que o aluno aprenda a selecionar a informação de que necessita e a registrar aquilo que é mais importante sobre 
um determinado assunto" (MEC, 1998, p. 144). Essa receita, assim como outros tipos de textos que estão representando a cultura indígena pelas mãos de seus próprios sujeitos, forçosamente o fazem com funcionalidade e legitimação cultural etnocêntrica. Para retomar os termos de Gee, constatase o impasse da impossibilidade de haver aquisição de um discurso secundário, quando a prática social não existe: "[s]i carecemos de acesso a la prática social, no nos introducimos en el discurso, no lo tenemos" (GEE, 2005, p. 145).

Outros tipos de texto ainda incluem:

- bilhetes, cartas, radiogramas, atas e ofícios,

- questionários, formulários e documentos pessoais,

- textos de jornais, revistas, folhetos publicitários e propagandas,

- textos científicos.

De maneira geral, são os tipos de textos que os estudantes não-índios praticam (só na escola). O leitor informado pode argumentar que, do modo como apresento a questão, obscureço a importância de o cidadão indígena ter acesso às modalidades formais do português. De fato, constata-se, imediatamente, a importância do que tratamos anteriormente de empoderamento Entretanto, poderíamos nos perguntar sobre a eficácia dessas práticas, inclusive nas escolas monolíngües, uma vez que as pesquisas sobre letramento em língua materna cada vez mais nos mostram um distanciamento das práticas do aluno em relação ao cânone escolar.

\section{Palavras finais}

A julgar pelos resultados do Pisa (Programa Internacional de Avaliação de Alunos), divulgados no dia 5 de dezembro de 2006 (INEP), em Brasilia, os estudantes brasileiros pouco entendem o que lêem. O Brasil ficou em último lugar, numa pesquisa que envolveu 32 países e avaliou, sobretudo, a compreensão de textos por alunos de 15 anos. Os estudantes brasileiros ficaram na última posição na prova de leitura.

A partir de nossa reflexão, podemos concluir que é extremamente importante considerarmos a dimensão do poder na formulação de uma proposta educacional para as escolas indígenas, sobretudo no que diz respeito ao ensino da prática de escrita e leitura como bens universais, descontextualizados e que servem para estimular a "tradução cultural". Não havendo prática escrita nas comunidades de fala, e não havendo, portanto, 
um discurso que a promova e sustente, que seja "autóctone", os moldes de práticas são importados da cultura dominante, e os alunos, tanto quanto nossos alunos escreventes em português, podem estar apenas seguindo um caminho que já provou estar, senão equivocado, altamente ineficiente.

Uma vez que as práticas letradas de diferentes comunidades (quando essas estão imersas em discursos de escrita) são muitas vezes distantes do enfoque que a escola costuma dar à escrita (o letramento tipicamente escolar), o letramento indígena deve problematizar essa diferença, por exemplo, na discussão das formas diversas de conceber e valorar a escrita, os diferentes usos, as várias linguagens, os possíveis posicionamentos do interlocutor, os graus diferenciados de familiaridade temática ou conteúdos referenciais.

Nesse sentido, a pergunta que deixamos sem resposta, mas que acreditamos necessário colocar e, assim, contribuir para futuras discussões, é sobre o valor e a necessidade de uma possível exportação, com os gêneros, de esquemas, de moldes discursivos escritos, do fracasso escolar de nossa sociedade e de suas terríveis conseqüências para o seio das comunidades indígenas. O contato com a nova palavra, tal como na citação de Bakhtin da introdução, é ele próprio dialógico: evolução para alguns, aculturação para outros. Assim, a leitura que propusemos do RCNEI procurou identificar pontos de trabalho para propiciar uma prática de letramento como interpretação recíproca, historicamente definida, dialógica e não ingênua quanto às malhas do poder envolvido.

Para concluir, apresento este questionamento, extremamente pertinente, que, embora coloque o valor da escrita em questão, é uma produção escrita indígena. Assim, mesmo em português, ao lado da nossa História da Escrita, alguns posicionamentos de professores indígenas nos mostram como seria escrita uma História (escrita) Indígena da Escrita.

No nosso ponto de vista a escrita foi e é responsável pela ambição e desigualdade social do Planeta, porque através da escrita criaram-se leis e normas. O que não deveria acontecer é que algumas pessoas que têm mais domínio da escrita acabam desvalorizando as pessoas que não dominam a escrita alfabética, mas que dominam a sua própria escrita, que acaba sendo desvalorizada e às vezes extinta pela influência da escrita alfabética. Então, nós perguntamos: será que essa evolução da escrita foi boa para todos nós? $(. . .)^{10}$

\footnotetext{
${ }^{10}$ Trecho extraído de BAY, Universidade indígena, A história da escrita (ver Bibliografia).
} 


\section{Referências Bibliográficas}

BAY, Universidade indígena. A história da escrita. Disponível em: <http:/ /www.letras.ufmg.br/bay/sites/xacriaba/historiadaescrita.htm>. Acesso em: 08 jan. 2007.

BAKHTIN, M. Marxismo e filosofia da linguagem. 8. ed. São Paulo: Hucitec, 1997.

BRASIL. Ministério da Educação. Programa para as escolas indigenas. Brasília: MEC, 1992.

BRASIL. Ministério da Educação. Referencial Curricular Nacional para as Escolas Indigenas. Brasília: MEC, 1998.

BRONCKART, Jean-Paul. Atividades de Linguagens, texto e discursos. Por um interacionismo sócio-discursivo. Trad. Anna Rachel Machado e Péricles Cunha. São Paulo: Educ, 1997.

CARDONA, G. R. Antropología de la escritura. Barcelona: Editorial Gedisa, 1994.

CHARTIER, R. A aventura do livro: do leitor ao navegador. São Paulo: Editora UNESP/ Imprensa Oficial do Estado, 1999.

FAIRCLOUGH, N. Discurso e mudança social. Brasília: UnB, 1992/2001.

FERREIRO, E. Cultura escrita e educação. Porto Alegre: Artes Médicas, 2001.

FOUCAULT, M. A arqueologia do saber. 7. ed. Rio de Janeiro: Forense Universitária, 2004.

GEE, J. P. La ideología en los discursos. Ediciones Morata. Colección Educación Crítica. Madrid, 2005.

GNERRE, M. Linguagem, escrita e poder. 4. ed. São Paulo: Martins Fontes, 2003.

GRAFF, H. J. The Literacy Myth: literacy and social structure in the nineteenth century city. New York and London: Academic Press, 1979.

GRAFF, H. J. Os labirintos da alfabetização: reflexões sobre o passado e o presente da alfabetização. Porto Alegre: Artes Médicas, 1994.

HARRIS, Roy. The language-makers. London: Duckworth, 1980.

KLEIMAN, A. B. Leitura: ensino e pesquisa. São Paulo: Pontes: 1989.

KLEIMAN, A. B. (Org.). Os significados do letramento: uma nova perspectiva sobre a prática social da escrita. Campinas, Mercado das Letras, 1995. 
LÉVI-STRAUSS, C. Tristes tropiques. Paris: Plon, 1974.

MANGUEL, Alberto. Uma história da leitura. Trad. Pedro Maia Soares. São Paulo: Companhia das Letras, 1997.

OLIVEIRA, G. M. O que quer a lingüística e o que se quer da lingüística na pedagogia da diferença? A delicada questão da assessoria ao movimento indígena. In: CONFERÊNCIA AMERÍNDIA DE EDUCAÇÃO - AMERÍNDIA: tecendo os caminhos da edcuação escolar. Anais.... Cuiabá, MT: Secretaria de Estado da Educação, 17 a 21 nov. 1997.

OLIVEIRA, G. M. de; OLIVEIRA, S. M. Formação de Professores: Um caso de Política Lingüística nas comunidades Kaingáng. In: I ENCONTRO DE VARIAÇÃO LINGÜÍSTICA DO CONE SUL, 1, 1996. Anais..., Porto Alegre, 2 a 4 set. 1996.

ROJO, R. Gêneros do discurso e gêneros textuais: Questões teóricas e aplicadas. In: MEURER, J. L. et al. (Org.). Gêneros: Teorias, métodos e debates. São Paulo: Parábola, 2005. p. 184-207.

TFOUNI, L. V. Letramento e alfabetização. São Paulo: Cortez, 1995. 